\title{
The repertoire of T-lymphocytes recovered by bronchoalveolar lavage from healthy nonsmokers
}

\author{
S.E. Burastero, B. Borgonovo, D. Gaffi, E. Frittoli, A. Wack, G.A. Rossi, E. Crimi
}

The repertoire of T-lymphocytes recovered by bronchoalveolar lavage from healthy nonsmokers. S.E. Burastero, B. Borgonovo, D. Gaffi, E. Frittoli, A. Wack, G.A. Rossi, E. Crimi. CERS Journals Ltd 1996.

ABSTRACT: We reasoned that persistent exposure to a limited set of airborne antigens could drive the preferential expansion of single $\mathrm{T}$-cell clones in the lower respiratory tract of normal individuals. To explore this issue, the normal human $\alpha / \beta$ T-cell receptor repertoire was studied in lung lymphocytes obtained by bronchoalveolar lavage (BAL) from the lumen of the lower respiratory tract.

BAL T-cells obtained from five healthy volunteers were first analysed using polymerase chain reaction to amplify all known $\mathrm{V} \alpha$ and $\mathrm{V} \beta$ genes of the T-cell receptor. T-cells from peripheral blood were used as an internal control. Heteroduplex analysis of the amplified products was then performed, to assess the clonal composition of the repertoire of lung- versus blood-derived T-lymphocytes within each amplified variable gene family.

In all subjects, the T-cell repertoire in the lung was largely as heterogeneous as peripheral blood in terms of clonal composition. This indicated lack of preferential expansion of single T-cell clones. A few T-cell clones were simultaneously expanded in blood and lung in all individuals within a limited number of $\mathrm{V} \beta$ (mean 2.4; range 2-4) and $V \alpha$ (mean 1.6; range 1-3) genes. We also found that lung $T$ lymphocytes expressed all of the $\mathrm{V}$ gene families of the $\mathrm{T}$-cell receptor that were expressed by peripheral blood T-cells.

Our results indicate that $\mathrm{T}$-cell clones in the lower respiratory tract of normal individuals are distributed according to a largely polyclonal pattern, which corresponds to that found in peripheral blood.

Eur Respir J., 1996, 9, 319-327.
DIBIT, San Raffaele Scientific Institute, Milan, Cattedra di Fisiopatologia Respiratoria, DISM, University of Genoa (EC) and Divisione di Pneumologia, Istituto G. Gaslini, Genoa (GAR), Italy.

Correspondence: E. Burastero DIBIT, San Raffaele Scientific Institute Via Olgettina 58 I-20132 Milan Italy

Keywords: Bronchoalveolar lavage T-lymphocytes immune repertoire T-cell receptor

Received: May 191995

Accepted after revision November 21995

Supported by grants No. 920419 (VII Progetto AIDS) from Istituto Superiore Sanità to SEB; by grant Ricerca Finalizzata "Farmacogenetrica" N.93.14.01F from Ministero della Sanità Rome to GAR.
The epithelial surface of the lower respiratory tract is constantly exposed to airborne environmental antigens, with a contact area that in humans is above 50 square metres. The T-lymphocytes homing at this site, usually obtained by bronchoalveolar lavage (BAL), have been characterized in normal individuals for a number of distinct phenotypic and functional features that, in general, support the hypothesis of a confined immunological compartment. In fact, lung lymphocytes display the very late activation-1 (VLA-1) surface antigens [1] at a much higher rate than early activation markers, such as the interleukin-2 (IL-2) receptor [2]. They also have low IL-2 messenger ribonucleic acid (mRNA) expression and a "memory" T-cell phenotype, as defined by the CD45 RO membrane molecule [3]. Therefore, it is likely that BAL T-cells represent a compartmentalized lymphoid population with a low capability of proliferation, that is thought to be less efficacious than other more organized structures in driving an optimal immunization against new antigens [4]. Accordingly, the lung epithelial surface may not be the site of a primary immune response [5]. Thus, it may be that immunization via the respiratory tract occurs via the transport of antigen to lung lymph nodes by macrophages [6] or by dendritic cells, well-characterized as highly efficient antigen presenting cells [7].

The repertoire of antigen specificities of lung T-cells is not known. One speculation is that the local T-cells represent the result of the selection by a persistent antigen challenge by a limited number of airborne antigens. Thus, a restricted repertoire of specificities, i.e. a selective expansion of single T-cell clones, would be expected. However, recirculation of T-cells from the lung to peripheral blood and vice versa is an important feature in chronic diseases, such as sarcoidosis and tuberculosis [8], as well as in atopic asthma $[9,10]$. This is confirmed in animal models [11], where preferential homing to the lung of lung-derived lymphocytes was demonstrated with adoptive transfer experiments. The combination of these characteristics makes it difficult to predict the degree of diversity generated by locally available antigen specificities in lung T-cells.

In order to explore this issue, five healthy volunteers were involved in the study. Fibreoptic bronchoscopy and BAL were performed in each subject. Polymerase chain reaction (PCR) was used to amplify the genes coding for the variable part of the T-cell receptor in BAL and peripheral blood T-cells. The variable (V) part of the T-cell 
receptor $(\mathrm{TcR})$ is the specific element of antigen recognition of T-lymphocytes that gives them the ability to bind antigens in the context of major histocompatibility complex (MHC) molecules of class I or II [12]. Finally, the heteroduplex assay was used to study the clonal composition of the T-cell repertoire. This assay can detect the presence and the relative amount of single $\mathrm{T}$-cell clones within each PCR amplified V gene fragment. With this approach, the pattern of clonality of the T-cells in the lung versus periphery was defined.

\section{Materials and methods}

\section{Experimental subjects}

Five healthy, lifetime nonsmoking volunteers (2 males and 3 females), with no history of pulmonary infection in the previous 6 months, were included in the study. Mean age was 33 (range 21-56 yrs). These subjects had a negative anamnesis for asthma and atopic diseases, a negative skin prick test for a panel of the 12 most common allergens in our country (Lolium perenne, Parietaria, Olea, Betula, Dermatophagoides pteronyssinus, Dermatophagoides farinae., Cupressus, cat dandruff, dog dandruff, Alternaria, Cladosporium, Aspergillus), a Tiffenau index and total pulmonary capacity in the normal range [13], and a negative response to methacholine challenge (inhaled cumulative dose $2.4 \mathrm{mg}$ ).

\section{Fibreoptic-bronchoscopy and BAL}

Bronchoscopy and BAL were performed as described previously [14]. Briefly, after premedication with atropine $(0.5 \mathrm{mg}$ i.m.) and diazepam (10 mg i.m.), local anaesthesia of the nostrils was achieved with lidocaine $2 \%$ and adrenaline $0.1 / 1000$ ( $1 \mathrm{~mL}$ each nostril). A fibreoptic bronchoscope (Olympus BF, type P10) was then passed through the nose. The pharynx and the large airways were anaesthetized by instillation of lidocaine $2 \%$, and the tip of the bronchoscope was wedged into a subsegmental branch of the right middle lobe. In patients Nos. 3, 4 and 5 the procedure was repeated in the lingula. Five aliquots of $20 \mathrm{~mL}$ each of sterile, warm $\left(37^{\circ} \mathrm{C}\right)$ saline were infused through the channel of the bronchoscope and recovered at a negative pressure of 5-120 $\mathrm{mmHg}$.

\section{$B A L$ sample processing}

The fluid recovered was filtered through two layers of sterile gauze and centrifuged at $250 \times \mathrm{g}$ for $5 \mathrm{~min}$ to separate the cells from the supernatants. The cell pellet was resuspended in ice cold phosphate-buffered saline (PBS) without $\mathrm{Ca}^{2+}$ and $\mathrm{Mg}^{2+}$, at a concentration of $10^{6}$ cells $\cdot \mathrm{mL}^{-1}$. A small sample of the cell suspension was centrifuged by using a cytocentrifuge (Cytospin, Shandon Southern Instruments, Sewickley, PA, USA) spinning approximately 100,000 cells at $500 \mathrm{rpm}$ for $5 \mathrm{~min}$ onto a glass slide. BAL cells were air-dried and stained with Diff-Quick staining (Merz \& Dade A.G., Dudingen, Switzerland). Cell differentials were determined by counting at least 300 cells per slide, using a light microscope (Carl Zeiss, Oberkochen, Germany). Macrophages, lymphocytes, neutrophils and eosinophils were expressed as percentage of total cells recovered. The remaining cells were immediately lysed in guanidium-isothiocyanate buffer and stored at $-20^{\circ} \mathrm{C}$ until ribonucleic acid (RNA) extraction. We did not in vitro amplify BAL cells with any mitogen (IL-2, PHA) before processing them, in order to study the T-cell repertoire without introducing in vitro any possible bias.

\section{Isolation of peripheral blood mononuclear cells}

In each subject, blood sampling was performed immediately before the beginning of the BAL procedure. Peripheral blood mononuclear cells (PBL) were isolated on a lymphoprep gradient (Sigma Chemical Co.) from heparinized blood, according to standard procedures.

\section{PCR analysis}

Total RNA was extracted from unfractionated BAL cells (numbers ranging from $6 \times 10^{5}$ to $3 \times 10^{7}$ ) and from $2 \times 10^{6} \mathrm{PBL}$ using the procedure described by CHOMOCZYNSKI and SACCHI [15]. All of the RNA was used for firststrand complementary deoxyribonucleic acid (cDNA) synthesis using an oligo (dT) primer and murine mammary leukaemia virus (MMLV) reverse transcriptase (BRL, Gaithersburg, MD, USA). Of each cDNA sample, $1 / 60$ was amplified using the $\mathrm{V} \alpha-\mathrm{C} \alpha$ or $\mathrm{V} \beta-\mathrm{C} \beta$ specific oligonucleotides described previously (table 1) $[16,17]$. PCR reactions were performed in a $30 \mu \mathrm{L}$ final volume using a Thermal Cycler 9600 (Perkin Elmer, Weiterstadt, Germany) under the following conditions: $30 \mathrm{~s}$ denaturation at $94^{\circ} \mathrm{C} ; 30 \mathrm{~s}$ annealing at $60^{\circ} \mathrm{C}$ for $\mathrm{V} \beta$ and at $61^{\circ} \mathrm{C}$ for $\mathrm{V} \alpha ; 30 \mathrm{~s}$ elongation at $72{ }^{\circ} \mathrm{C}$ for 35 cycles preceded by $3 \mathrm{~min}$ of denaturation and followed by $5 \mathrm{~min}$ for final elongation. One third of the amplified products was run on a $2 \%$ agarose, ethidium bromide stained gel; pBr322 MspI digested DNA was used as a molecular weight marker (New England Biolabs, Beverley, MA, USA).

\section{Heteroduplex analysis}

The remaining PCR amplified product was subsequently run on a $12 \%$ native polyacrylamide gel electrophoresis (PAGE) $[18,19]$. In summary, $20 \mu \mathrm{L}$ of each amplified fragment was heated at $94^{\circ} \mathrm{C}$ for $5 \mathrm{~min}$ to denature DNA, and then reannealed for $1 \mathrm{~h}$ at $50^{\circ} \mathrm{C}$ and kept at $4^{\circ} \mathrm{C}$ until gel loading. This temperature is permissive for reannealing between strains with minor mismatches (heteroduplex) as well as between homologous strains (homoduplex). $\mathrm{V} \alpha$ and $\mathrm{V} \beta$ amplified fragments derived from peripheral blood and BAL of the same subject were 
Table 1. - Oligonucleotides used in PCR

\begin{tabular}{|c|c|c|c|}
\hline $\mathrm{V} \alpha$ & & $\mathrm{V} \beta$ & \\
\hline 1 & 5'GGCATTAAGGGTTTTGAGGCTGGA & 1 & 5'GCACAACAGTTCCCTGACTTGCAC \\
\hline 2 & 5'CAGTGTTCCAGAGGGAGCCATTGT & 2 & 5'TCATCAACCATGCAAGCCTGACCT \\
\hline 3 & 5'CCCGGGCAGCAGACACTGCTTCTTA & 3 & 5'GTCTCTAGAGAGAAGAAGGAGCGC \\
\hline 4 & 5'TTGGTATCGACAGCTTCACTCCCA & 4 & 5'ACATATGAGAGTGGATTTGTCATT \\
\hline 5 & 5'CGGCCACCCTGACCTGCAACTATA & 5.1 & 5'ATACTTCAGTGAGACACAGAGAAAC \\
\hline 6 & 5'TCCGCCAACCTTGTCATCTCCGCT & $5.2-5$ & 5'TTCCCTAACTATAGCTCTGAGCTG \\
\hline 7 & 5'GCAACATGCTGGCGGAGCACCCAC & 5.6 & 5'TGCTAATGAGTTAAGGAGATCAG \\
\hline 8 & 5'CATTCGTTCAAATGTGGGCAAAAG & 6 & 5'AGGCCTGAGGGATCCGTCTC \\
\hline 9 & 5'CCAGTACTCCAGACAACGCCTGCA & 7 & 5'CCTGAATGCCCCAACAGCTCTC \\
\hline 10 & 5'CACTGCGGCCCAGCCTGGTGATAC & 8 & 5'ATTTACTTTAACAACAACGTTCCG \\
\hline 11 & 5'CGCTGCTCATCCTCCAGGTGCGGG & 9 & 5'CCTAAATCTCCAGACAAAGCT \\
\hline 12 & 5'TCGTCGGAACTCTTTTGATGAGCA & 10 & 5'CTCCAAAAACTCATCCTGTACCTT \\
\hline 13 & 5'TTCATCAAAACCCTTGGGGACAGC & 11 & 5'TCAACAGTCTCCAGAATAAGGACG \\
\hline 14 & 5'CCCAGCAGGCAGATGATTCTCGTT & 12 & 5'AAAGGAGAAGTCTCAGAT \\
\hline 15 & 5'TTGCAGACACCGAGACTGGGGACT & 13.1 & 5'CAAGGAGAAGTCCCCAAT \\
\hline 16 & 5'TCAACGTTGCTGAAGGGAATCCTC & 13.2 & 5'GGTGAGGGTACAACTGCC \\
\hline 17 & 5'TGGGAAAGGCCGTGCATTATTGAT & 14 & 5'GTCTCTCGAAAAGAGAAGAGGAAT \\
\hline 18 & 5'CAGCACCAATTTCACCTGCAGCTT & 15 & 5'AGTGTCTCTCGACAGGCACAG \\
\hline 19 & 5'ACACTGGCTGCAACAGCATCCAGG & 16 & 5'AAAGAGTCTAAACAGGATGAGT \\
\hline 20 & 5'TCCCTGTTTATCCCTGCCGACAGA & 17 & 5'CAGATAGTAAATGACTTTCAG \\
\hline 21 & 5'AGCAAAATTCACCATCCCTGAGCG & 18 & 5'GATGAGTCAGGAATGCCAAAGGAA \\
\hline 22 & 5'CCTGAAAGCCACGAAGGCTGATGA & 19 & 5'CAATGCCCCAAGAACGCACCCTG \\
\hline 23 & 5'TGCCTCGCTGGATAAATCATCAGG & 20 & 5'AGCTCTGAGGTGCCCCAGAAT \\
\hline 24 & 5'CTGGATGCAGACACAAAGCAGAGC & 21 & 5'ATTCACAGTTGCCTAAGGATCGA \\
\hline 25 & 5'TGGCTACGGTACAAGCCGGACCCT & 22 & 5'GGGCAGAAAGTCGAGTTTCTGGTT \\
\hline 26 & 5'AGCGCAGCCATGCAGGCATGTACC & 23 & 5'TTTATGAAAAGATGCAGAGCGAT \\
\hline 27 & 5'AAGCCCGTCTCAGCACCCTCCACA & 24 & 5'AAGTCAAGTCAGGCCCCAAAGCT \\
\hline 28 & 5'TGGTTGTGCACGAGCGAGACACTG & & \\
\hline 29 & 5'GAAGGGTGGAGAACAGATGCGTCG & & \\
\hline $\mathrm{C} \alpha$ & & $C \beta$ & \\
\hline $5^{\prime} \mathrm{C}$ & ГАTCTGTTTCAAAGCTTTTCTCGACCAG & & TGACCCCACTGTCGACCTCCTTCCCATT \\
\hline
\end{tabular}

PCR: polymerase chain reaction.

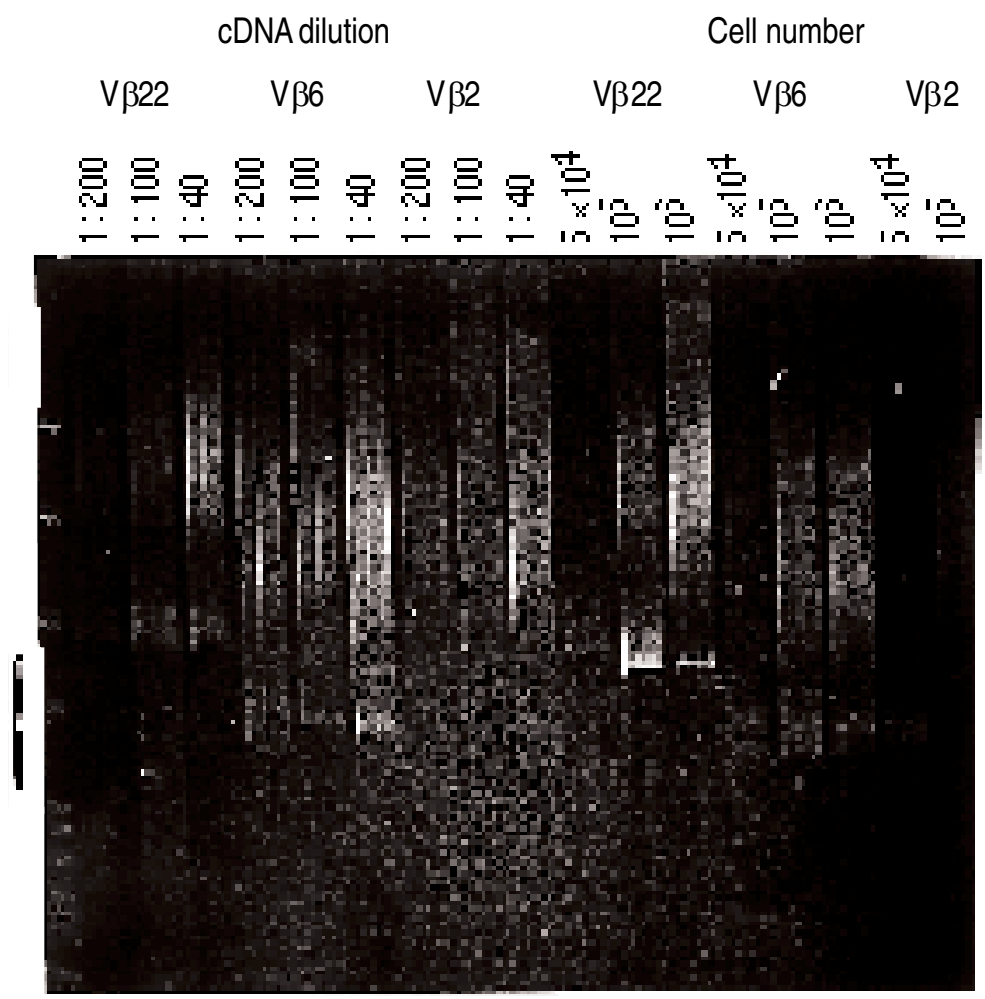

Fig. 1. - Heteroduplex analysis of polyclonal T-cells consistently yielded a smear at increasing dilution of cDNA and at decreasing cell numbers. Three widely represented $V \beta$ families (as indicated) were studied in peripheral blood T-cells from a laboratory worker by using PCR and subsequent heteroduplex analysis of the amplified products. The assay was performed, for each $\mathrm{V} \beta$, at three different dilutions of the cDNA contained in the original $30 \mu \mathrm{L}$ reaction volume $\left(1: 200,1: 100\right.$ and 1:40) and at three different cell doses $\left(5 \times 10^{4}, 5 \times 10^{5}\right.$ and $\left.5 \times 10^{6}\right)$. Bracket indicates where the homoduplex bands migrate (varying between 300 and 400 base pairs). cDNA: complementary deoxyribonucleic acid; PCR: polymerase chain reaction. 
run in parallel lanes for comparison of the heteroduplex and homoduplex bands. Gels were run at $10 \mathrm{~mA}$ overnight at $4{ }^{\circ} \mathrm{C}$, stained with ethidium bromide and photographed. The presence of a single homoduplex band indicated expansion of a single T-cell clone, multiple heteroduplex bands indicated oligoclonal expansion of T-cell clones, and the presence of a smear (both as heteroduplex and/or as homoduplex) reflected a polyclonal Tcell population. At first, the number of emerging bands was determined by three independent observers. The result was then discussed until they reached an agreement.

Sampling error could occur because of the low level of T-cells in the BAL once their T-cell receptors are further amplified by PCR. A single clonotype could emerge and then over-represent the in vivo distribution. To assess this possibility, experiments were performed in which cDNA was exhaustively diluted and others where the cell number from which RNA was extracted and the cDNA prepared were progressively lowered. V $\beta 2, \mathrm{~V} \beta 6$ and V $\beta 22$ specific probes were used as representative of widely used $\mathrm{V}$ gene families.

In order to establish the limit of detection of single clones in our system, we performed an experiment where a single T-cell clone (TCC A) was mixed at different cell doses with a constant amount $\left(8 \times 10^{6}\right)$ of a polyclonal population of peripheral blood T-cells from a normal donor (not included in the BAL study). Heteroduplex analysis was then performed on the PCR amplified product of the V $\beta$ gene family expressed by that clone. Thus, detection of one single emerging band was expected. Moreover, in order to mimic the situation where two T-cell clones in a polyclonal population are expanded within a given $\mathrm{V}$ gene family, two T-cell clones were used which expressed the V $\beta 17$ gene (denominated TCC $\mathrm{A}$ and TCC B) both CD4+, expressing two different $\mathrm{J} \beta$ and $\mathrm{D} \beta$ genes. They were raised from a seronegative donor against the gp120 envelope protein of the HIV-1 virus (curtesy of L. Furci). These two T-cell clones were mixed (TCC A: $2 \times 10^{6}$ cells; TCC B: $10^{5}$ cells) with a polyclonal population of T-lymphocytes obtained from peripheral blood of the same normal donor $\left(8 \times 10^{6}\right.$ cells $)$, and the heteroduplex assay was then performed. Two heteroduplex and two homoduplex bands were expected in this case.

\section{Results}

Heteroduplex assay on T-cell receptor gene segments at low cell number and high cDNA dilution in peripheral blood lymphocytes

This assay did not introduce signs of oligoclonality in a polyclonal T-cell sample in forms of emerging bands, either at high cDNA dilution or at low cell number (fig. 1). In both cases, a weakening of the smear was observed at cDNA dilution (1:200) or at number of cells $\left(10^{5}\right)$ lower than those usually handled when analysing BAL T-lymphocytes.
Sensitivity of the heteroduplex assay in detecting single $T$-cell clone in a polyclonal population and pattern of bands expected in the case of the expansion of two Tcell clones within a given $V \beta$ family

The sensitivity of the heteroduplex assay in detecting a single T-cell clone mixed in a polyclonal population of T-lymphocytes was around 1 cell out of 3,200 (fig. 2 ). When two clones (expressing the same $V \beta$ ) were mixed in a polyclonal population of T-lymphocytes, the following pattern was found: two homoduplex bands and two heteroduplex bands, superimposed to a smear corresponding to the polyclonal population of peripheral Tcells (fig. 2).

\section{$B A L$ cellularity}

Subjects characteristics, total number of cells recovered by BAL and proportions of the different cell types are shown in table 2. Lack of erythrocytes and low numbers of polymorphonuclear leucocytes indicated that BAL was not contaminated by peripheral blood.

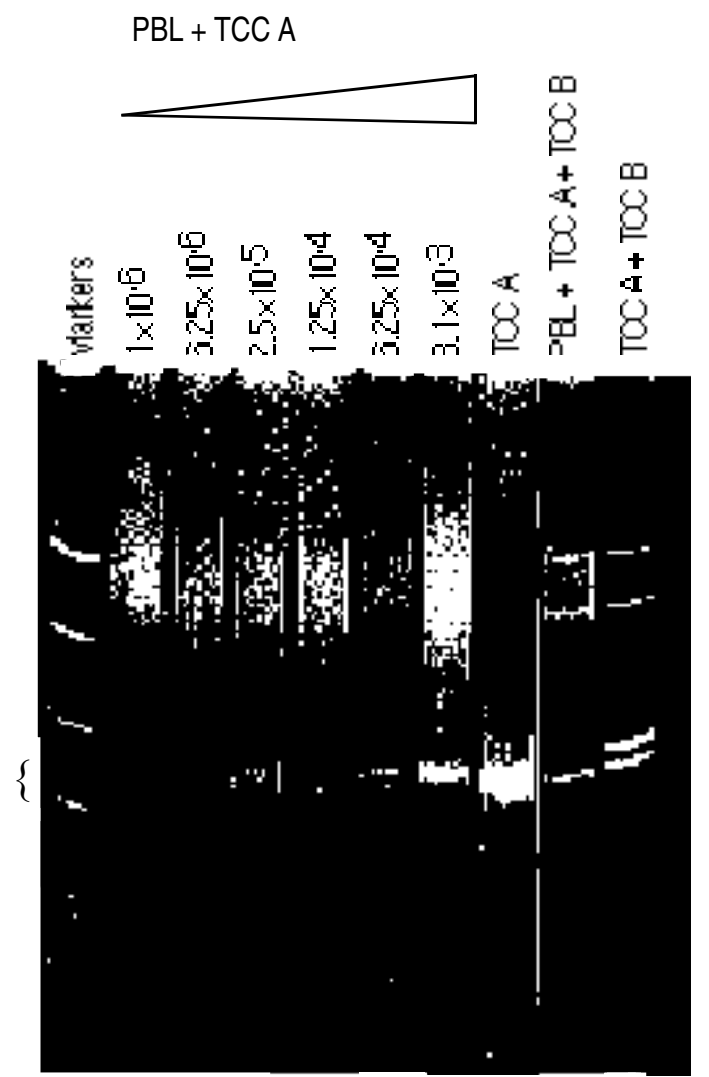

Fig. 2. - The sensitivity of the heteroduplex assay was assessed in the detection of a single T-cell clone (TCC A, V $\beta 17$ ) mixed with a constant number $\left(8 \times 10^{6}\right)$ of peripheral blood mononuclear cells (PBL) to emulate the physiological condition where a single T-cell clone is expanded in a polyclonal population of T-lymphocytes. The ratio between the number of T-cells from TCC A and the number of PBL is indicated. Heteroduplex analysis of TCC A $\left(2 \times 10^{6}\right.$ cells $)+$ a second T-cell clone expressing the same V $\beta$ (TCC B, $10^{5}$ cells) + peripheral blood T-cells $\left(8 \times 10^{6}\right.$ cells) are shown as an example of the result expected when a biclonal expansion is taking place in a polyclonal population of PBL (TCC A + TCC B + PBL). 
Table 2. - Cellular components of bronchoalveolar lavage

\begin{tabular}{|c|c|c|c|c|c|}
\hline & \multicolumn{5}{|c|}{ Subject No. } \\
\hline & 1 & 2 & 3 & 4 & 5 \\
\hline Age yrs & 33 & 21 & 56 & 24 & 29 \\
\hline Sex & $\mathrm{F}$ & M & $\mathrm{F}$ & M & M \\
\hline \multicolumn{6}{|l|}{ Right middle lobe } \\
\hline Total cell number $\times 10^{6}$ & 5.0 & 8.7 & 4.5 & 2.4 & 2.9 \\
\hline Macrophages \% & 88 & 94 & 91 & 89 & 93 \\
\hline Lymphocytes \% & 10 & 5 & 7 & 6 & 5 \\
\hline Neutrophils $\%$ & 1 & 1 & 1 & 4 & 1 \\
\hline Eosinophils & 1 & 0 & 1 & 1 & 1 \\
\hline \multicolumn{6}{|l|}{ Lingula } \\
\hline Total cell number $\times 10^{6}$ & ND & ND & 4.9 & 3.1 & 3.1 \\
\hline Macrophages \% & & & 89 & 95 & 92 \\
\hline Lymphocytes \% & & & 10 & 5 & 6 \\
\hline Neutrophils $\%$ & & & 1 & 0 & 1 \\
\hline Eosinophils & & & 0 & 0 & 1 \\
\hline
\end{tabular}

M: male; F: female; ND: not determined.

$V$ gene usage by $\alpha / \beta$ T-cell receptor positive lymphocytes in the lung versus peripheral blood

Gene segments belonging to virtually all the single $\mathrm{V} \beta$ genes of the panel tested could be amplified by PCR from cDNA obtained by T-lymphocytes from peripheral blood as well as from BAL in the five individuals studied (not shown). A representative result (subject No. 1) is shown in figure 3. In figure 4, results of PCR on Tcells from two segments of the same lung (subject No. 3 ) are shown. Although no quantitative information can be obtained concerning the relative usage of single variable genes coding for the $\alpha / \beta$ T-cell receptor, there was not any single $\mathrm{V} \beta$ gene amplifiable from peripheral blood which was excluded from lung T-lymphocytes in all individuals studied. Analysis of $\mathrm{V} \alpha$ genes gave similar results (not shown).

Clonal composition of the $T$-cell receptor repertoire in the lung versus peripheral blood

Heteroduplex analysis of the amplified PCR products obtained from peripheral blood and from BAL cells yielded a smear type of pattern in the vast majority of $\mathrm{V}$ genes analysed. This reflected the polyclonality of Tcells within each $\mathrm{V}$ gene family (figure 5 shows representative results of heteroduplex analysis of $\mathrm{V} \beta 1,2,5.1$, 6,7 and 22 gene segments amplified from peripheral blood and from BAL T-lymphocytes in subject No. 1). Polyclonality of BAL T-cells was confirmed by the analysis of the $\mathrm{V} \alpha$ genes (not shown). In a limited number of $\mathrm{V}$ gene products, co-migrating bands were simultaneously detected both in the peripheral blood- and in the lung-derived sample. Overall, the mean number of emerging bands was 2.4 among V $\beta$ genes (range 2-4) and 1.6 among $\mathrm{V} \alpha$ genes (range 1-3). Single V gene products where an expanded band was visible are listed in table 3. Representative examples of these bands are shown in figure $5(\mathrm{~V} \beta 5.1)$ and figure 6 (fig. 6a from subject No. 2; fig. 6 b from subject No. 3). In subjects where BAL samples were available from two different lung segments, co-migrating bands were present in both (fig. 6b). In subjects Nos. 3 and 5 a $\mathrm{V}$ gene product was found (V $\beta 7$ and V $\beta 13.1$, respectively) which showed an expanded band in the peripheral blood-derived sample not accompanied by a corresponding expanded band in the BAL-derived sample (table 3 ).

PCR, TcR V $\beta$
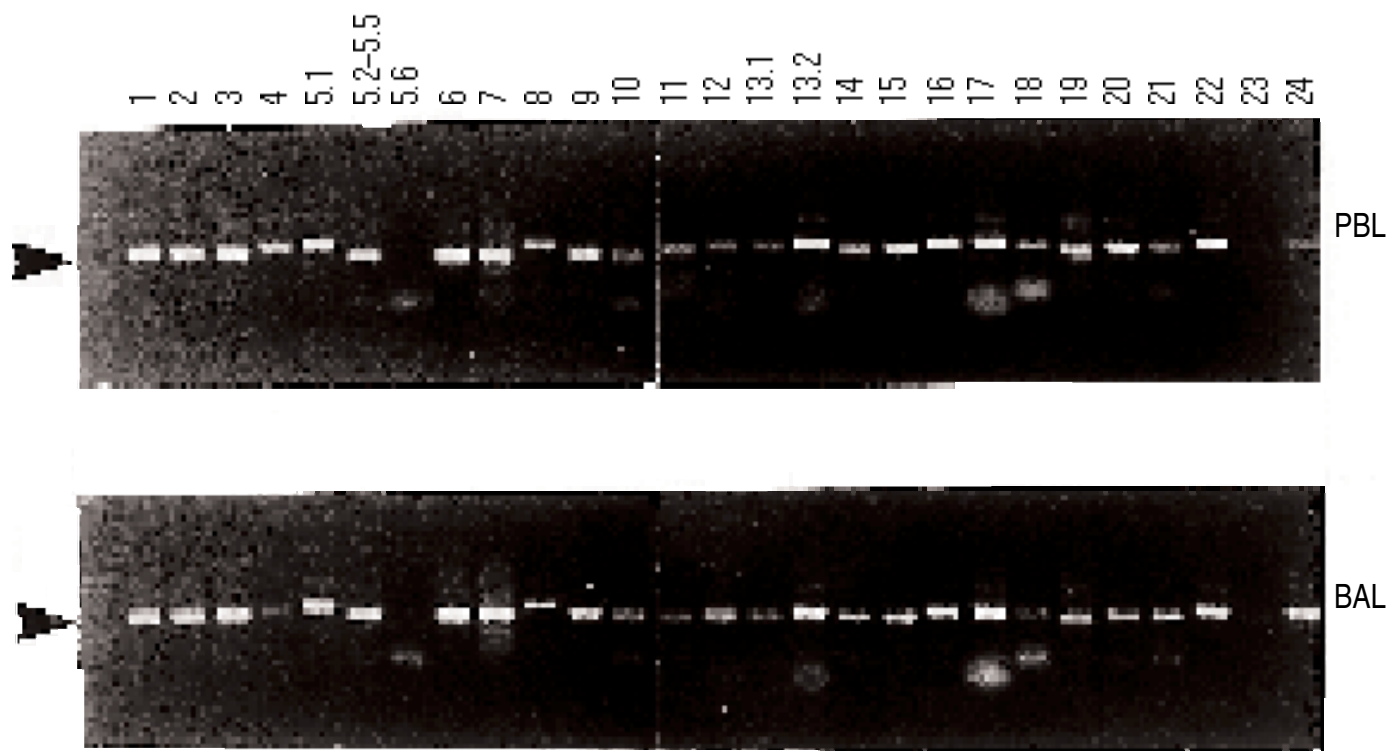

Fig. 3. - Polymerase chain reaction (PCR) analysis of T-cell receptor (TcR) V $\beta$ genes in bronchoalveolar lavage (BAL) and peripheral blood from subject No. 1. PCR products obtained using the panel of V $\beta$ gene specific oligonucleotides described in table 1 on the cDNA derived from peripheral blood lymphocytes (PBL) and BAL T-cells. Arrow heads indicate the 307 base pair fragment. 
PCR, TCR V $\beta$

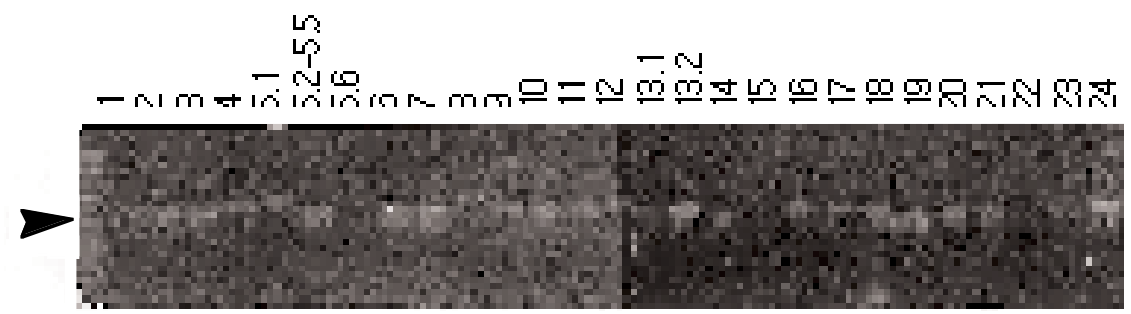

PBL

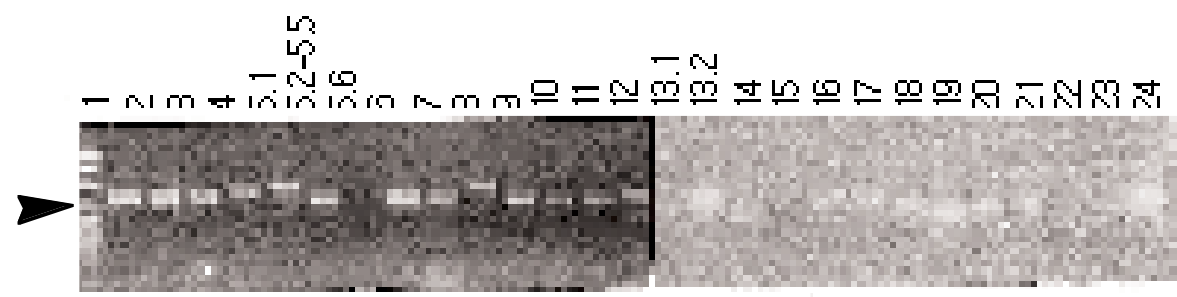

Right middle lobe

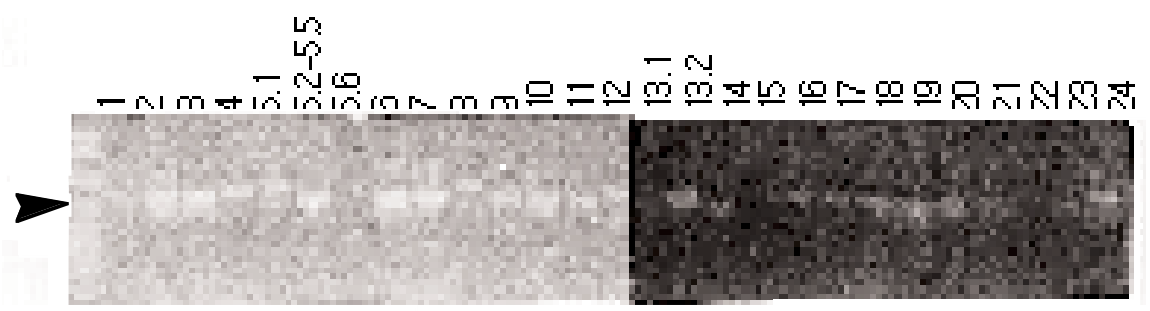

Lingula

Fig. 4. - Polymerase (PCR) analysis of T-cell receptor (TcR) V $\beta$ genes in bronchoalveolar lavage (BAL) performed in two different segments and peripheral blood from subject No. 3. For explanation see legend to figure 3. Cells from symmetrical sites of the two lungs were analysed, as indicated. PBL: peripheral blood lymphocytes.

\section{HETERODUPLEX,TCR V $\beta$}

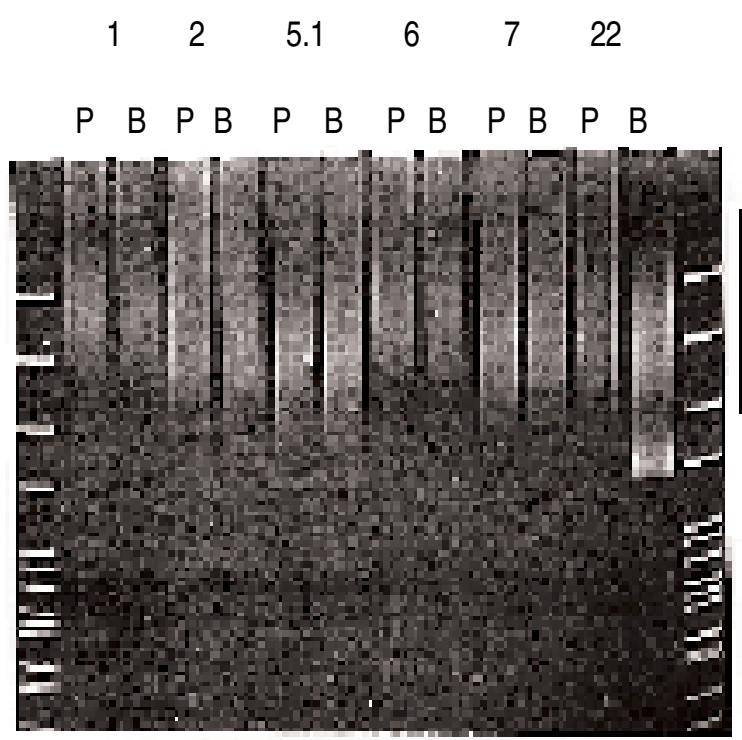

Fig. 5. - Heteroduplex assay of BAL and peripheral blood T-cells from subject No. 1. Heteroduplex analysis of PCR products of five representative $\mathrm{V} \beta$ genes (listed on top), comparing peripheral blood (P) and BAL (B) derived T-cells. The vertical line indicates the region where the smear is distributed.
Table 3. - $\mathrm{V}$ gene products which yielded a single expanded band at heteroduplex analysis

\begin{tabular}{|c|c|c|c|c|}
\hline $\begin{array}{l}\text { Subject } \\
\text { No. }\end{array}$ & $\begin{array}{l}\text { TcR } \\
\mathrm{V} \text { gene }\end{array}$ & PBL & BAL 1 & BAL 2 \\
\hline \multirow[t]{3}{*}{1} & Vß5.1 & + & + & ND \\
\hline & V $\beta 10$ & + & + & \\
\hline & $\mathrm{V} \alpha 4$ & + & + & \\
\hline \multirow[t]{7}{*}{2} & $\mathrm{~V} \beta 2$ & + & + & ND \\
\hline & $\mathrm{V} \beta 14$ & + & + & \\
\hline & $V \beta 21$ & + & + & \\
\hline & $\mathrm{V} \beta 22$ & + & + & \\
\hline & $\mathrm{V} \alpha 2$ & + & + & \\
\hline & $\mathrm{V} \alpha 4$ & + & + & \\
\hline & $\mathrm{V} \alpha 20$ & + & + & \\
\hline \multirow[t]{3}{*}{3} & $\mathrm{~V} \beta 7$ & + & - & - \\
\hline & $\mathrm{V} \beta 8$ & + & + & + \\
\hline & $\mathrm{V} \alpha 21$ & + & + & + \\
\hline \multirow[t]{4}{*}{4} & $\mathrm{~V} \beta 1$ & + & + & + \\
\hline & V $\beta 5$ & + & + & + \\
\hline & Va6 & + & + & + \\
\hline & $V \alpha 17$ & + & + & + \\
\hline \multirow[t]{3}{*}{5} & $V \beta 13.1$ & + & - & - \\
\hline & $\mathrm{V} \beta 7$ & + & + & + \\
\hline & $V \alpha 7$ & + & + & + \\
\hline
\end{tabular}

TcR: T-cell receptor; V: variable part; PBL: peripheral blood mononuclear cells (lymphocytes); BAL: bronchoalveolar lavage. 
a)

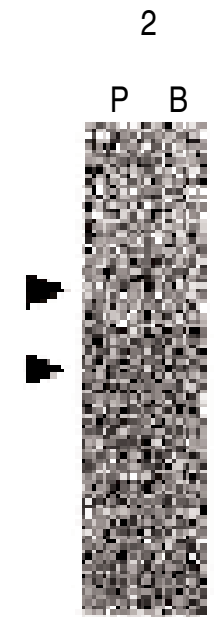

14

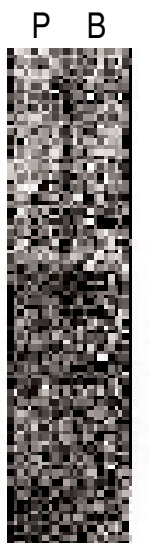

21

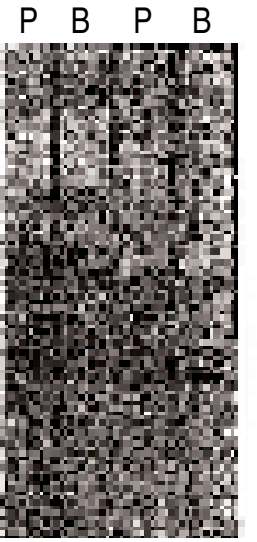

b)

HETERODUPLEX, TcR V $\beta$

Fig. 6. - V genes from BAL and peripheral blood T-cells from subject No. 2 and No. 3 (a) and b), respectively) where expanded bands were observed. Heteroduplex analysis of PCR products of the V $\beta$ genes (listed on top), comparing peripheral blood (P) and BAL (B) derived T-cells. $\mathrm{B} 1$ and B2 indicate two different lung segments of subject No. 3 from which BAL T-cells were recovered. The vertical lines indicate the region where the smear is distributed. Arrows indicate the positions of 527 and 307 molecular weight markers.

\section{Discussion}

The results of this study indicate that in the normal lower respiratory tract the T-cell repertoire is qualitatively similar to the peripheral blood, not only in terms of $\mathrm{V}$ gene usage (all $\mathrm{V}$ gene families of the $\mathrm{T}$-cell receptor are represented) but also in terms of degree of diversity (prevalent polyclonality). A limited number of expanded clones is present in the BAL T-cell repertoire, which are detectable in the periphery as well. We conclude that a large repertoire of T-cells with different antigen specificities is maintained in the lumen of the normal lower respiratory tract. The heteroduplex assay represents a technological novelty, compared to other methods for studying the relative usage of the different $\mathrm{V}$ gene families (quantitative PCR, V $\beta$ specific monoclonal antibodies). In fact, this assay reveals the clonal composition of T-cells within each population of T-lymphocytes expressing a given $\mathrm{V}$ gene family. This approach can discriminate situations where predominant clones emerge (e.g. for the effect of an antigen drive) from others where the population of single T-cells is distributed in a homogeneous (polyclonal) fashion.

The lung is a model of a normal tissue chronically exposed to antigens. Inhaled antigens reach the bronchial mucosa at the upper and/or lower respiratory tract with a pattern dependent on the size of the particles that carry them [20]. Lung lymphocytes represent a population of mature differentiated T-cells that developed in lung lymph nodes as antigen specific effector cells. This probably occurred during acute exposure to invaders or otherwise immunologically relevant substances; subsequently, these cells have migrated to the lung mucosa [21]. Alveolar macrophages, physiologically endowed with inhibitory functions over T-lymphocytes [4], in certain circumstances allow antigen presentation and local T-cell activation (e.g. in a fraction of patients with asthma) [22].
Thus, they could significantly influence the progression of the immune response in atopic mucosas. Indeed, we recently demonstrated oligoclonal T-cell expansion upon antigen provocation in BAL T-cells from atopic asthmatics [23]. T-cells obtained by BAL represent the epithelium-associated lymphocytes. How much of this cell population is segregated and how much is actively recirculating is a matter of debate [21]. In fact, the pattern of adhesion molecules expressed by lung lymphocytes is suggestive of the defined homing properties of a resident cell population $[1,2]$; on the other hand, recirculation of disease-associated lymphocytes has been found in the course of certain diseases characterized by chronic inflammation (tuberculosis, sarcoidosis) [8], or in individuals with atopic asthma [9, 10].

The investigation of the clonal composition of antigen specific T-cells is a novel approach to the study of the immune response in the lung. Although antigen specific T-cells have been isolated and cloned from BAL samples obtained from atopic individuals [24], to our knowledge, there is still no information available on the overall distribution of the T-cell repertoire in the lower respiratory tract in healthy individuals. The $\alpha / \beta$ T-cell receptor is the element of antigen recognition of MHC class I and II restricted (CD3+) T-lymphocytes [12].

Amplification with PCR of the genes coding for the $\mathrm{T}$-cell receptor is a valuable procedure in ascertaining the presence of T-lymphocytes which express a given $\mathrm{V}$ gene family. In this work, PCR was used as a first step in screening, to assess whether qualitative differences (absence or presence of clones using each single known $\mathrm{V}$ gene) could be seen in the lung versus the periphery. This analysis was further extended with the heteroduplex assay [18, 19], to assess the clonal composition within each V gene family. This assay is based on the principle that a mixture containing highly homologous DNA can renature after boiling not only by reannealing 
of homologous strains (homoduplex), but also of partly heterologous ones (heteroduplex). The latter migrate in a polyacrylamide nondenaturing gel with a higher apparent molecular weight. Moreover, heteroduplexes composed by the same but complementary strains are endowed with different migration properties (see figure 2, TCC A + TCC B). By applying this method to the analysis of the T-cell receptor in peripheral blood T-cells [18, 19], a typical smear-type distribution of bands representing the multiplicity of the T-cell clones is obtained. This result depicts the extreme polyclonality and heterogeneity of the peripheral repertoire.

A theoretical limit of the heteroduplex assay is the small sample size, either in terms of low cell number or of high cDNA dilution. This fact could over-represent the frequency of single T-cell clones, since PCR is made in a nonquantitative fashion. In preliminary tests, working with cell numbers in the range of those contained in BAL samples, we demonstrated that neither a limiting number of T-cells nor a high cDNA dilution caused the artificial appearance of emerging bands (fig. 1). In addition, we tested the sensitivity of our assay by titrating the number of T-cells in a polyclonal T-cell population; frequencies of single $\mathrm{T}$-cell clones in the range of $1 / 3,200$ could be detected as emerging bands by our method (fig. 2).

In agreement with a previous report by other investigators [25] we found that all known V $\beta$ T-cell receptor genes that are expressed in peripheral blood T-cells can also be detected in T-cells recovered from the lower respiratory tract (figs. 3 and 4). The novel finding of this study is that we found a T-cell receptor repertoire in the lung that was as heterogeneous and polyclonal as that found in peripheral blood (fig. 5). Moreover, when single emerging bands were visible in the periphery, they were present in the lung-derived sample as well (fig. 6 and table 3 ). These may represent populations of chronically expanded clones, that have been described in normal individuals and whose function is still debated [18]. In this case, one has to hypothesize that they possess homing receptor for the lung tissue. Alternatively, they may be T-cells specific for respiratory antigens, which expanded in the lymph nodes and recirculated back to the site of antigen encounter. However, the negative anamnesis for respiratory diseases in the last 6 months discourages this hypothesis.

We want to make the following points about the results of this study: 1) our method was sensitive to modifications of the lung T-cell repertoire, which induce the appearance of emerging bands; and 2) the lung Tcell repertoire in healthy subjects did not show organspecific signs of clonal expansion (as one could expect in a segregated immune compartment). In individuals who underwent BAL in two different lung segments, these single expanded bands were present in samples derived from both (fig. 6 and table 3), indicating a homogeneous distribution of the lung T-cell repertoire in different areas of this organ. In conclusion, in physiological conditions the persistent exposure to airborne antigens does not imply the local expansion of single $\mathrm{T}$-cell clones and/or the unbalanced homing to the lumen of the lower respiratory tract of single T-cell clones with selected antigen specificities.

Acknowledgements: The authors thank S. Oddera for skilful technical help and D. Morpurgo for helpful, friendly discussion.

\section{References}

1. Saltini C, Hember ME, Crystal RG. T-lymphocytes compartmentalized on the epithelial surface of the lower respiratory tract express the very late activation antigen complex, VLA-1. Clin Immunol Immunopathol 1988; 46: 221-233.

2. Muller-Quernheim J, Saltini C, Sondermeyer P, Crystal RG. Compartmentalized activation of IL-2 gene by lung T-lymphocytes in active pulmonary sarcoidosis. J Immunol 1986; 137: 3475-3483.

3. Saltini C, Kirbi M, Trapnell BC, Tamura N. Biased accumulation of T-lymphocytes with memory type CD45 leukocyte common antigen gene expression on the epithelial surface of the human lung. J Exp Med 1990; 171: $1123-1140$.

4. Holt PG. Downregulation of the immune response in the lower respiratory tract: the role of alveolar macrophages. Clin Exp Immunol 1986; 62: 261-270.

5. Orme IM, Collinf FM Aerogenic vaccination of mice with Mycobacterium bovis BCG. Tubercle 1986; 67: 133-140.

6. Harmsen AG, Muggenbury BA, Sniper MB, Bice DE. The role of macrophages in particle translocation from lung to lymph nodes. Science 1985; 230: 1277.

7. Schon-Hegrad MA, Oliver J, McMenamin PG, Holt PG. Studies on the density, distribution and surface phenotype of intraepithelial class II MHC complex (Ia) antigen-bearing dendritic cells in the conducting airways. $J$ Exp Med 1991; 173: 1345-1356.

8. Balbi N, Valle MT, Oddera S, et al. T-lymphocytes $\gamma \delta+$ with $\mathrm{V} \delta 2+$ antigen receptors are present in increased numbers in a fraction of patients with tuberculosis or sarcoidosis. Am Rev Respir Dis 1993; 148: 1685-1690.

9. Gerblich AA, Salik H, Schuyler MR. Dynamic T-cell changes in peripheral blood and bronchoalvelar lavage after antigenic provocation in asthmatics. Am Rev Respir Dis 1990; 143: 533-537.

10. Burastero SE, Fenoglio D, Crimi E, Brusasco V, Rossi GA. Frequency of allergen specific T-cells in blood and bronchial response to allergen challenge in asthma. $J$ Allergy Clin Immunol 1993; 91: 1075-1081.

11. Binns RM, Licence ST, Pabst R. Homing of blood, splenic and lung emigrant lymphoblasts: comparison with the behaviour of lymphocytes from these sources. Intern Immunol 1992; 4: 1011-1019.

12. Jogersen JL, Reay PA, Ehrich EW, Davis M. Molecular components of T-cell recognition. Ann Rev Immunol 1992; 10: 835-873.

13. Quanjer PH. Standardized lung function testing. Report of working party on standardization of lung function testing. European Coal and Steel Community (ECSC). Bull Eur Physiopathol Respir 1983; 19 (Suppl. 5): 1-94.

14. Rossi GA, Crimi E, Oddera S, Gianiorio P, Brusasco V. Late-phase asthmatic reaction to inhaled allergen is associated with early recruitment of eosinophils in the airways. Am Rev Respir Dis 1991; 144: 379-383.

15. Chomoczynski P, Sacchi N. Single step method of RNA 
isolation by acid guanidium thiocyanate-phenol-chloroform extraction. Anal Biochem 1987; 126: 156-161.

16. Genevee C, Diu A, Nierat J, et al. An experimentally validated panel of subfamily-specific oligonucleotide primers (V $\alpha 1-w 29 / \mathrm{V} \beta 1-w 24)$ for the study of human T-cell receptor variable gene segment usage by polymerase chain reaction. Eur J Immunol 1992; 22: 12611269.

17. Choi Y, Kotzin B, Herron L, Callahan J, Marrack P, Kappler J. Interactions of Staphylococcus aureus toxin superantigens with human T- cells. Proc Natl Acad Sci USA 1989; 243: 217-227.

18. Dellabona P, Padovan E, Casorati G, Brockhause M, Lanzavecchia A. An invariant $\mathrm{V} \alpha 24 / \mathrm{J} \alpha \mathrm{Q} / \mathrm{V} \beta 11 \mathrm{~T}$-cell receptor is expressed in all individuals by clonally expanded CD4-8- T-cells. J Exp Med 1994; 180: 1171-1176.

19. Giachino C, Rocci MP, De Libero G, Oderda G, Ansaldi $\mathrm{N}$, Migone N. An alternative approach to the assessment of $\gamma \delta$ T-cell clonality in coeliac disease intestinal lesions through cDNA heteroduplex analysis of T-cell receptor V-J junctions. Hum Immunol 1994; 40: 303-311.
20. Frieke Kuper C, Koornstra PJ, Hameleers DMH, et al. The role of nasopharyngeal lymphoid tissue. Immunol Today 1992; 13: 119-122.

21. Pabst R. Is BALT a major component of the human lung immune system? Immunol Today 1992; 13: 119122.

22. Gant V, Cluzel M, Shakoor Z, Jon Rees P, Lee TH, Hamblin AS. Alveolar macrophage accessory cell function in bronchial asthma. Am Rev Respir Dis 1992; 146: 900-904.

23. Burastero SE, Crimi E, Balbo A, et al. Oligoclonality of lung T-lymphocytes following allergen inhalation in asthma. J Immunol 1995; 155: (in the press).

24. Del Prete G, DeCarli M, D'Elios M, et al. Allergen exposure induces the activation of allergen specific Tcells in the airway mucosa of patients with allergic diseases. Eur J Immunol 1993; 23: 1445-1449.

25. Dohi M, Yamamoto K, Masuko K, et al. Accumulation of multiple T-cell clonotypes in lungs of healthy individuals and patients with pulmonary sarcoidosis. $J$ Immunol 1994; 152: 1983-1988. 